\title{
Review
}

\section{The impact of minimally invasive surgeries for the treatment of symptomatic benign prostatic hyperplasia on male sexual function: a systematic review}

\author{
Ryan W. Frieben ${ }^{1}$, Hao-Cheng Lin $^{1,2}$, Peter P. Hinh ${ }^{1}$, Francesco Berardinelli ${ }^{1,3}$, Steven E. Canfield ${ }^{1,4}$, Run Wang ${ }^{1,4}$ \\ ${ }^{1}$ Division of Urology, University of Texas Medical School at Houston, Houston, TX 77030, USA \\ ${ }^{2}$ Department of Urology, Affiliated Drum Tower Hospital, Nanjing University School of Medicine, Nanjing 210008, China \\ ${ }^{3}$ Division of Urology, Department of Medicine and Aging Sciences, "G.d'Annunzio” University, Chieti, Italy \\ ${ }^{4}$ Department of Urology, University of Texas MD Anderson Cancer Center, Houston, TX 77030, USA
}

\begin{abstract}
A systematic review of randomized controlled trials and cohort studies was conducted to evaluate data for the effects of minimally invasive procedures for treatment of symptomatic benign prostatic hyperplasia (BPH) on male sexual function. The studies searched were trials that enrolled men with symptomatic BPH who were treated with laser surgeries, transurethral microwave therapy (TUMT), transurethral needle ablation of the prostate (TUNA), transurethral ethanol ablation of the prostate (TEAP) and high-intensity frequency ultrasound (HIFU), in comparison with traditional transurethral resection of the prostate (TURP) or sham operations. A total of 72 studies were identified, of which 33 met the inclusion criteria. Of the 33 studies, 21 were concerned with laser surgeries, six with TUMT, four with TUNA and two with TEAP containing information regarding male sexual function. No study is available regarding the effect of HIFU for BPH on male sexual function. Our analysis shows that minimally invasive surgeries for BPH have comparable effects to those of TURP on male erectile function. Collectively, less than $15.4 \%$ or $15.2 \%$ of patients will have either decrease or increase, respectively, of erectile function after laser procedures, TUMT and TUNA. As observed with TURP, a high incidence of ejaculatory dysfunction (EjD) is common after treatment of BPH with holmium, potassium-titanyl-phosphate and thulium laser therapies $(>33.6 \%)$. TUMT, TUNA and neodymium:yttrium aluminum garnet visual laser ablation or interstitial laser coagulation for $\mathrm{BPH}$ has less incidence of $\mathrm{EjD}$, but these procedures are considered less effective for $\mathrm{BPH}$ treatment when compared with TURP.
\end{abstract}

Asian Journal of Andrology (2010) 12: 500-508. doi: 10.1038/aja.2010.33; published online 17 May 2010.

Keywords: benign prostatic hyperplasia, ejaculatory dysfunction, erectile dysfunction, minimally invasive surgery, sexual function, transurethral resection of the prostate

Correspondence to: Dr Run Wang, Department of Urology, University of Texas Medical School at Houston and University of Texas MD Anderson Cancer Center, 6431 Fannin Street, MSB 6.018, Houston, TX 77030, USA.

Fax: +1-713-500-0546

Received: 26 February 2010

Accepted: 8 April 2010
E-mail: run.wang@uth.tmc.edu

Published online: 17 May 2010 Revised: 8 April 2010

\section{Introduction}

Benign prostatic hyperplasia $(\mathrm{BPH})$ is a chronic and often progressive condition that affects nearly three in four men by the seventh decade of life. Clinically, $\mathrm{BPH}$ is distinguished by progressive development 
of lower urinary tract symptoms (LUTSs) [1]. The other common disorder affecting aging men is sexual dysfunction. Sexual dysfunction encompasses not only erectile dysfunction, but also ejaculation abnormalities, difficulty in reaching orgasm, decreased libido and overall dissatisfaction. Both BPH and sexual dysfunction have a significant impact on the quality of life in older men $[2,3]$. Many studies suggest that the presence of LUTS is a risk factor for sexual dysfunction $[1,4]$. A large number of aging men with $\mathrm{BPH}$ will seek treatment. In the last decade, minimally invasive procedures have become the most popular options for surgical treatment of BPH with LUTS [3]. Minimally invasive procedures for BPH include, but are not limited to, transurethral laser procedures, transurethral microwave therapy (TUMT), transurethral needle ablation (TUNA), transurethral ethanol ablation of the prostate (TEAP) and high-intensity frequency ultrasound (HIFU). Even though the effectiveness of these minimally invasive surgeries for symptomatic BPH has been established in many studies, when compared with the gold standard surgical treatmenttransurethral resection of the prostate (TURP) [3], the impact of currently used minimally invasive surgeries for the treatment of BPH on male sexual function has not been well established. Our goal is to determine and compare the impact of these procedures with TURP on male sexual function after the treatment of $\mathrm{BPH}$.

\section{Materials and methods}

\subsection{Search strategy}

The search was restricted to studies in the English language from 1995 to April 2010. The MEDLINE was searched using the headings $\mathrm{BPH}$, holmium laser, potassium-titanyl-phosphate (KTP) or green light laser, thulium, neodymium:yttrium aluminum garnet (Nd:YAG), TUMT, TUNA, TEAP, HIFU for BPH, minimally invasive procedures for treatment of $\mathrm{BPH}$, TURP, sexual function, erectile dysfunction, impotence, retrograde ejaculation, decreased ejaculate volume, painful ejaculation and sexual satisfaction. The Cochrane Library and reference lists of all identified trials and previous reviews were also searched.

\subsection{Selection criteria}

The studies included were trials that enrolled men with symptomatic BPH who were treated with laser surgeries, TUMT, TUNA, TEAP or HIFU in comparison with traditional TURP or sham operations. Attention was given to studies that included data pertaining to the impact of these minimally invasive procedures for the treatment of BHP on sexual function. The selected studies included data relating to erectile function, sexual function, impotence, painful ejaculation, retrograde ejaculation, decreased ejaculate volume or overall sexual satisfaction.

\subsection{Data extraction and study appraisal}

The retrieved articles were reviewed for eligibility, and data were extracted on study characteristics, enrollment criteria, treatment allocation, follow-up duration and completeness, clinical outcomes and adverse events.

\section{Results}

\subsection{Study subjects and characteristics}

The combined search strategies identified 72 reports of trials, of which 33 met the inclusion criteria. Overall, 15 comparison studies between laser surgeries and TURP, which are used for the treatment of BPH, and their effects on male sexual function were analyzed. These included two trials that evaluated multiple minimally invasive procedures. There were also five cohort studies and one case series that reported the effect of laser surgeries on male sexual function. For TUMT, four comparison trials and two cohort studies were analyzed. For TUNA, three comparison trials to TURP and one cohort study were analyzed. Only two cohort studies that reported the effect of TEAP on male sexual function were identified. No study is available regarding the effect of HIFU for $\mathrm{BPH}$ on sexual function in men.

\subsection{Holmium laser versus TURP}

Eight randomized control trials that compared the holmium laser with TURP are summarized in Table 1 [5-12]. A total of 390 men were randomized to the holmium laser group and 370 men to the TURP group. The average follow-up in the studies was 21 months. Of the eight studies, six provided data pertaining to erectile function without using any validated questionnaires [5-9, 12]. Two studies used the International Index of Erectile Function questionnaire (IIEF) to assess the sexual function both before and after the procedures $[10,11]$. When all the study data were analyzed together, it was obvious that holmium laser 
Table 1. Effect of holmium laser versus TURP for BPH on sexual function.

\begin{tabular}{|c|c|c|c|c|c|c|c|c|c|c|c|}
\hline \multirow{2}{*}{$\begin{array}{l}\text { Authors and } \\
\text { study year }\end{array}$} & \multirow{2}{*}{$\begin{array}{l}\text { Study } \\
\text { design }\end{array}$} & \multirow{2}{*}{$\begin{array}{l}\text { Follow-up } \\
\text { (months) }\end{array}$} & \multicolumn{2}{|c|}{ Patient $(n)$} & \multirow{2}{*}{$\begin{array}{c}\text { Validated } \\
\text { questionnaire }\end{array}$} & \multicolumn{2}{|c|}{$\downarrow \mathrm{EF}(\%)$} & \multicolumn{2}{|c|}{$\uparrow \mathrm{EF}(\%)$} & \multicolumn{2}{|c|}{ EjD (\%) } \\
\hline & & & Laser & TURP & & Laser & $\overline{\text { TURP }}$ & Laser & TURP & Laser & TURP \\
\hline $\begin{array}{l}\text { Mottet et al. } \\
1999 \text { [5] }\end{array}$ & RCT & 12 & 23 & 13 & No & 10 & 0 & - & - & 50 & 50 \\
\hline $\begin{array}{l}\text { Gilling et al. } \\
2000[6]\end{array}$ & RCT & 24 & 61 & 59 & No & 8 & 11 & 20 & 19 & 96 & 86 \\
\hline $\begin{array}{l}\text { Tan et al. } \\
2003[7]\end{array}$ & $\mathrm{RCT}$ & 12 & 31 & 30 & No & 3.9 & 3.9 & 3.9 & 3.9 & - & - \\
\hline $\begin{array}{l}\text { Kuntz et al. } \\
2004[8]\end{array}$ & $\mathrm{RCT}$ & 12 & 100 & 100 & No & 11.2 & 10.5 & 3.3 & 0 & 74 & 70.3 \\
\hline $\begin{array}{l}\text { Westenberg et al. } \\
2004 \text { [9] }\end{array}$ & $\mathrm{RCT}$ & 48 & 61 & 59 & No & 8 & 17 & 10 & 7 & - & - \\
\hline $\begin{array}{l}\text { Montorse et al. } \\
2004[10]\end{array}$ & $\mathrm{RCT}$ & 12 & 52 & 48 & IIEF & No & No & - & - & - & - \\
\hline $\begin{array}{l}\text { Briganti et al. } \\
2006[11]\end{array}$ & $\mathrm{RCT}$ & 24 & 32 & 31 & IIEF & No & No & 1.7 & 3.4 & 78.3 & 78.3 \\
\hline $\begin{array}{l}\text { Wilson et al. } \\
2006 \text { [12] }\end{array}$ & $\mathrm{RCT}$ & 24 & 30 & 30 & No & 3.9 & 3.9 & 3.9 & 3.9 & 75 & 62 \\
\hline Weighted mean & & $21.0 \pm 12.4$ & $\begin{array}{c}390 \\
\text { (total) }\end{array}$ & $\begin{array}{c}370 \\
\text { (total) }\end{array}$ & & $7.5 \pm 3.0$ & $7.7 \pm 6.2$ & $7.1 \pm 6.9$ & $6.2 \pm 6.7$ & $74.7 \pm 16.4$ & $69.3 \pm 14.0$ \\
\hline
\end{tabular}

Abbreviations: $\mathrm{BPH}$, benign prostate hyperplasia; EF, erectile function; EjD, ejaculatory dysfunction; IIEF, International Index of Erectile Function; RCT, randomized control trial; TURP, transurethral resection of the prostate; -, not reported.

surgery had the same effect as TURP on erectile function in men. There were about $7.5 \%$ (range from $3.9 \%$ to $11.2 \%$ ) and $7.7 \%$ (range from $0 \%$ to $17 \%$ ) of patients reporting decreased erectile function after the holmium laser procedures and TURP, respectively. Interestingly, there were about $7.1 \%$ (range from $1.7 \%$ to $20 \%$ ) and $6.2 \%$ (range from $0 \%$ to $19 \%$ ) of patients reporting increased erectile function after each surgery. There were high incidences of ejaculatory dysfunction (mainly retrograde ejaculation or decreased ejaculates) after both holmium laser (range from $50 \%$ to $96 \%$ ) and TURP (range from $50 \%$ to $86 \%$ ) procedures for BPH. The cohort study with holmium laser surgery also concurred with the finding from the randomized control trials. In a cohort study of 108 patients reported by Meng et al. [13], with the use of the Danish Prostate Symptom Score Sexual Function Questionnaire (DanPSS Sex) to examine the change in sexual function in patients before and after the use of the holmium laser for the treatment of $\mathrm{BPH}$, there were $2 \%$ of the patients with new onset of severe erectile dysfunction at the 6-month follow-up. However, there were 3\% of the patients with improved erections and $2 \%$ of the patients with increase in satisfaction of their sex life and libido. The ejaculatory dysfunction was also very common, with $21 \%$ of the patients reporting pain or discomfort with ejaculation and $70 \%$ of the patients having retrograde ejaculation.

\subsection{KTP laser versus TURP}

Table 2 summarizes the three randomized control trials that compared the KTP laser with TURP [14-16]. Collectively, 127 men were randomized to the KTP laser group and 125 men to the TURP group. The follow-up interval ranged from 6 to 36 months. Two studies used the validated questionnaires to evaluate the erectile function, and found no overall change before and after KTP laser and TURP procedures [15, 16]. The KTP laser and TURP caused high and equal incidence of ejaculatory dysfunction with ranges from $17.2 \%$ to $49.9 \%$ for KTP laser and from $9.1 \%$ to $56.7 \%$ for TURP. Two cohort studies were also analyzed and collectively included a total of 100 patients with a 12- and 24-month follow-up [17, 18]. One of these cohort studies assessed erectile function by means of IIEF [18], and the other one did not use any validated 
Table 2. Effect of KTP laser versus TURP for BPH on sexual function.

\begin{tabular}{|c|c|c|c|c|c|c|c|c|c|}
\hline \multirow{2}{*}{$\begin{array}{l}\text { Authors and } \\
\text { study year }\end{array}$} & \multirow{2}{*}{$\begin{array}{l}\text { Study } \\
\text { design }\end{array}$} & \multirow{2}{*}{$\begin{array}{l}\text { Follow-up } \\
\text { (months) }\end{array}$} & \multicolumn{2}{|c|}{ Patient $(n)$} & \multirow{2}{*}{$\begin{array}{c}\text { Validated } \\
\text { questionnaire }\end{array}$} & \multicolumn{2}{|c|}{$\downarrow \mathrm{EF}(\%)$} & \multicolumn{2}{|c|}{$\mathrm{EjD}(\%)$} \\
\hline & & & Laser & TURP & & Laser & TURP & Laser & TURP \\
\hline $\begin{array}{l}\text { Shingleton et al. } \\
2002 \text { [14] }\end{array}$ & RCT & 36 & 50 & 50 & No & - & - & 17.2 & 9.1 \\
\hline $\begin{array}{l}\text { Bouchier-Hayes et al. } \\
2006 \text { [15] }\end{array}$ & RCT & 12 & 38 & 38 & BSFQ & No & No & - & - \\
\hline $\begin{array}{l}\text { Horasanli et al. } \\
2008[16]\end{array}$ & $\mathrm{RCT}$ & 6 & 39 & 37 & IIEF & No & No & 49.9 & 56.7 \\
\hline Weighted mean & & $18.0 \pm 15.9$ & $\begin{array}{c}127 \\
\text { (total) }\end{array}$ & $\begin{array}{c}125 \\
\text { (total) }\end{array}$ & & & & $33.6 \pm 2$ & $2.9 \pm 33.7$ \\
\hline
\end{tabular}

Abbreviations: BSFQ, Baseline Sexual Function Questionnaire; BPH, benign prostate hyperplasia; EF, erectile function; EjD, ejaculatory dysfunction; IIEF, International Index of Erectile Function; KTP, potassium-titanyl-phosphate; RCT, randomized control trial; TURP, transurethral resection of the prostate; -, not reported.

questionnaires [17]. However, both studies showed no new development of erectile dysfunction after KTP laser surgery for the treatment of BPH. The rate of retrograde ejaculation was high at the early stage after the procedure, but there was a trend of decreasing retrograde ejaculation with longer follow-up, with 3-, 6-, 12- and 24-month follow-up having rates of $29 \%$, $21 \%, 15 \%$ and $9 \%$, respectively [17].

\subsection{Thulium laser versus TURP}

The only randomized control trial comparing the thulium laser with the TURP was reported by Xia et al. [19] There were 52 patients who received thulium laser surgery, and 48 patients who were randomized to TURP with a follow-up of 12 months. They did not address erectile function; however, they did report a prevalence of $55 \%$ and $65 \%$ of retrograde ejaculation after thulium laser and TURP treatments, respectively. The case series that enrolled 72 men was published by $\mathrm{Fu}$ et al. [20]. They reported no change in erectile function at the 12-month follow-up. Retrograde ejaculation was reported in $19 \%$ and $10 \%$ of the patients at the 3-month and 12-month follow-up, respectively.

\subsection{ND:YAG visual laser ablation of the prostate versus TURP}

Although VLAP and interstitial laser coagulation (ILC) have largely been abandoned in the treatment of BPH because of their inferior results and high retreatment rates compared with the TURP [3], the impact of this laser modality on sexual function is included for completeness. Three randomized control trials and one cohort study with multiple groups that compared the ND:YAG laser with the TURP are summarized in Table 3 [21-24]. A total of 176 men were treated with ND:YAG laser and 168 patients underwent TURP. The follow-up interval ranged from 3 to 12 months. Two studies used validated questionnaires to evaluate sexual function $[23,24]$. When all study data were analyzed collectively, ND:YAG laser surgery had the same effect as TURP on erectile function in men. There were about $15.4 \%$ (ranging from $5.5 \%$ to $22.2 \%$ ) and $14.8 \%$ (ranging from $3.5 \%$ to $26.5 \%$ ) of patients reporting decreased erectile function after the ND:YAG laser procedures and TURP, respectively. Interestingly, in the cohort study with multiple groups, there were $7.9 \%$ and $20.4 \%$ of patients reporting increased erectile function after ND:YAG and TURP [24]. ND:YAG laser appears to have less ejaculatory dysfunction (ranging from 3\% to $35 \%$ ) when compared with TURP (ranging from $15 \%$ to $80 \%$ ), although a large (227 patients) single-group cohort study [25] reported a $27 \%$ rate of retrograde ejaculation after ND:YAG laser.

\subsection{TUMT versus TURP}

Four comparative studies between TUMT and TURP were identified and are summarized in Table 4 [23, 24, 26, 27]. All together, these studies looked at 190 patients who underwent TUMT and 148 patients who underwent TURP. The length of follow-up reported ranged from 3 to 60 months. Two studies used the validated questionnaires to evaluate sexual function $[24,27]$. Collectively, TUMT had less adverse effects on sexual function, with $8.7 \%$ of patients (ranging from $0 \%$ to $18.2 \%$ ) reporting decreased erectile function and $17.8 \%$ (ranging from $9.2 \%$ to 
Table 3. Effect of Nd:YAG laser versus TURP for BPH on sexual function.

\begin{tabular}{|c|c|c|c|c|c|c|c|c|c|c|c|}
\hline \multirow{2}{*}{$\begin{array}{l}\text { Authors and } \\
\text { study year }\end{array}$} & \multirow{2}{*}{$\begin{array}{l}\text { Study } \\
\text { design }\end{array}$} & \multirow{2}{*}{$\begin{array}{l}\text { Follow-up } \\
\text { (months) }\end{array}$} & \multirow{2}{*}{$\begin{array}{c}\text { Validated } \\
\text { questionnaire }\end{array}$} & \multicolumn{2}{|c|}{ Patient $(n)$} & \multicolumn{2}{|c|}{$\downarrow \mathrm{EF}(\%)$} & \multicolumn{2}{|c|}{$\uparrow \mathrm{EF}(\%)$} & \multicolumn{2}{|c|}{ EjD (\%) } \\
\hline & & & & Laser & TURP & Laser & TURP & Laser & $\overline{\text { TURP }}$ & Laser & TURP \\
\hline $\begin{array}{l}\text { Cowles et al. } \\
1995 \text { [21] }\end{array}$ & RCT & 12 & No & 56 & 59 & 5.5 & 3.5 & - & - & - & - \\
\hline $\begin{array}{l}\text { Sengor et al. } \\
1996 \text { [22] }\end{array}$ & RCT & 6 & No & 30 & 30 & - & - & - & - & 3 & 80 \\
\hline $\begin{array}{l}\text { Nørby et al. } \\
2002 \text { [23] }\end{array}$ & RCT & 6 & DANPSS-1 & 48 & 24 & 22.2 & 14.3 & - & - & 35 & 50 \\
\hline $\begin{array}{l}\text { Arai et al. } \\
2000[24]\end{array}$ & Cohort $^{*}$ & 3 & SMUSFQ & 42 & 55 & 18.4 & 26.5 & 7.9 & 20.4 & 8 & 15 \\
\hline Weighted mean & & $6.8 \pm 3.8$ & & $\begin{array}{c}176 \\
\text { (total) }\end{array}$ & $\begin{array}{c}168 \\
\text { (total) }\end{array}$ & $15.4 \pm 8.8$ & $14.8 \pm 11.5$ & 7.9 & 20.4 & $15.3 \pm 17.2$ & $48.3 \pm 32.5$ \\
\hline
\end{tabular}

Abbreviations: BPH, benign prostate hyperplasia; DANPSS-1: Danish Prostatic Symptom Score; EF, erectile function; EjD, ejaculatory dysfunction; Nd:YAG, neodymium:yttrium aluminum garnet; RCT: randomized control trial; SMUSFQ, Sapporo Medical University Sexual Function Questionnaire; TURP, transurethral resection of the prostate; -, not reported; ${ }^{*}$, cohort with multiple groups.

Table 4. Effect of TUMT versus TURP for BPH on sexual function.

\begin{tabular}{|c|c|c|c|c|c|c|c|c|c|c|c|}
\hline \multirow{2}{*}{$\begin{array}{l}\text { Authors and } \\
\text { study year }\end{array}$} & \multirow{2}{*}{$\begin{array}{l}\text { Study } \\
\text { design }\end{array}$} & \multirow{2}{*}{$\begin{array}{l}\text { Follow-up } \\
\text { (months) }\end{array}$} & \multicolumn{2}{|c|}{ Patient $(n)$} & \multirow{2}{*}{$\begin{array}{l}\text { Validated } \\
\text { questionnaire }\end{array}$} & \multicolumn{2}{|c|}{$\downarrow \mathrm{EF}(\%)$} & \multicolumn{2}{|c|}{$\uparrow \mathrm{EF}(\%)$} & \multicolumn{2}{|c|}{ EjD (\%) } \\
\hline & & & TUMT & TURP & & TUMT & TURP & TUMT & TURP & TUMT & TURP \\
\hline $\begin{array}{l}\text { Ahmed et al. } \\
1997[26]\end{array}$ & RCT & 6 & 30 & 30 & No & 0 & 21.1 & - & - & 22.2 & 63.2 \\
\hline $\begin{array}{l}\text { Nørby et al. } \\
2002[23]\end{array}$ & $\mathrm{RCT}$ & 6 & 46 & 24 & DANPSS-1 & 9.1 & 14.3 & - & - & 22 & 50 \\
\hline $\begin{array}{l}\text { Mattiasson et al. } \\
2007 \text { [27] }\end{array}$ & $\mathrm{RCT}$ & 60 & 80 & 39 & No & 7.5 & 15.4 & - & - & - & - \\
\hline $\begin{array}{l}\text { Arai et al. } \\
2000[24]\end{array}$ & Cohort $^{*}$ & 3 & 34 & 55 & SMUSFQ & 18.2 & 26.5 & 15.2 & 20.4 & 9.2 & 15 \\
\hline Weighted mean & & $8.8 \pm 27.5$ & $\begin{array}{c}190 \\
\text { (total) }\end{array}$ & $\begin{array}{c}148 \\
\text { (total) }\end{array}$ & & $8.7 \pm 7.5$ & $19.3 \pm 5.6$ & 15.2 & 20.4 & $17.8 \pm 7.4$ & $42.7 \pm 20.3$ \\
\hline
\end{tabular}

Abbreviations: BPH, benign prostate hyperplasia; DANPSS-1, Danish Prostatic Symptom Score; EF, erectile function; EjD, ejaculatory dysfunction; RCT, randomized control trial; SMUSFQ, Sapporo Medical University Sexual Function Questionnaire; TUMT, transurethral microwave therapy; TURP, transurethral resection of the prostate; - , not reported; ${ }^{*}$, cohort with multiple groups.

$22.2 \%$ ) of patients reporting ejaculatory dysfunction compared with TURP, which had $19.3 \%$ (ranging from $14.3 \%$ to $26.5 \%$ ) of patients with erectile dysfunction and $42.7 \%$ (ranging from $15 \%$ to $63.2 \%$ ) of patients with ejaculatory dysfunction. Again, interestingly, in the cohort study with multiple groups, there were $15.2 \%$ and $20.4 \%$ of patients reporting increased erectile function after TUMT and TURP, respectively [24]. The effect of TUMT on sexual function was also compared with a sham procedure in a large, multicenter, randomized study [28]. During 6-month followup, $14.3 \%$ of the TUMT patients had some forms of ejaculatory dysfunction including hematospermia, abnormal ejaculation or painful ejaculation. This was compared with the sham-treated patients, who had $1.4 \%$ incidence of ejaculatory dysfunction. Only one case of erectile dysfunction was reported in the TUMT group, and this was attributed to improper placement of the probe during the procedure. The minimal adverse effect of TUMT on sexual function was also confirmed by a single-group cohort study with no incidence of erectile dysfunction and $11 \%$ ejaculatory dysfunction at the total of 24 months follow-up after TUMT [29]. 
Table 5. Effect of TUNA versus TURP for BPH on sexual function.

\begin{tabular}{|c|c|c|c|c|c|c|c|c|c|c|c|}
\hline \multirow{2}{*}{$\begin{array}{l}\text { Authors and } \\
\text { study year }\end{array}$} & \multirow{2}{*}{$\begin{array}{l}\text { Study } \\
\text { design }\end{array}$} & \multirow{2}{*}{$\begin{array}{l}\text { Follow-up } \\
\text { (months) }\end{array}$} & \multicolumn{2}{|c|}{ Patient $(n)$} & \multirow{2}{*}{$\begin{array}{c}\text { Validated } \\
\text { questionnaire }\end{array}$} & \multicolumn{2}{|c|}{$\downarrow \mathrm{EF}(\%)$} & \multicolumn{2}{|c|}{$\uparrow \mathrm{EF}(\%)$} & \multicolumn{2}{|c|}{ EjD (\%) } \\
\hline & & & TUNA & TURP & & TUNA & TURP & TUNA & TURP & TUNA & TURP \\
\hline $\begin{array}{l}\text { Bruskewitz et al. } \\
1998 \text { [30] }\end{array}$ & RCT & 12 & 65 & 56 & No & 0 & 12.7 & - & - & 13 & 54 \\
\hline $\begin{array}{l}\text { Cimentepe et al. } \\
2003[31]\end{array}$ & RCT & 18 & 26 & 33 & IIEF & 0 & 12 & - & - & 0 & 48.5 \\
\hline $\begin{array}{l}\text { Hill et al. } \\
2004[32]\end{array}$ & RCT & 60 & 65 & 56 & No & 3.1 & 21.4 & - & - & 0 & 41.1 \\
\hline $\begin{array}{l}\text { Arai et al. } \\
2000[24]\end{array}$ & Cohort $^{*}$ & 3 & 42 & 55 & SMUSFQ & 20 & 26.5 & 7.9 & 20.4 & 9.2 & 15 \\
\hline Weighted mean & & $23.3 \pm 25.3$ & $\begin{array}{c}198 \\
\text { (total) }\end{array}$ & $\begin{array}{c}200 \\
\text { (total) }\end{array}$ & & $5.8 \pm 9.6$ & $18.2 \pm 7.1$ & 7.9 & 20.4 & $5.6 \pm 6.6$ & $39.7 \pm 17.3$ \\
\hline
\end{tabular}

Abbreviations: BPH, benign prostate hyperplasia; EF, erectile function; EjD, ejaculatory dysfunction; RCT, randomized control trial; SMUSFQ, Sapporo Medical University Sexual Function Questionnaire; TUNA, transurethral needle ablation; TURP, transurethral resection of the prostate; -, not reported; ", cohort with multiple groups.

\subsection{TUNA versus TURP}

Table 5 shows three randomized control trials and one cohort study that compared TUNA with TURP [24, 30-32]. Collectively, 198 patients were treated with TUNA and 200 patients underwent TURP. The follow-up interval ranged from 3 to 60 months. Two studies used validated questionnaires to evaluate erectile function $[24,31]$. All these studies showed that TUNA had less adverse effects on sexual function, with $5.8 \%$ of patients (ranging from $0 \%$ to $20 \%$ ) reporting decreased erectile function and 5.6\% (ranging from $0 \%$ to $13 \%$ ) of patients reporting ejaculatory dysfunction, compared with TURP, which had $18.2 \%$ (ranging from $12 \%$ to $26.5 \%$ ) of patients with erectile dysfunction and $39.7 \%$ (ranging from $15 \%$ to $54 \%$ ) of patients with ejaculatory dysfunction. Not surprisingly, in the cohort study with multiple groups, there were $7.9 \%$ and $20.4 \%$ of patients reporting increased erectile function after TUNA and TURP, respectively [24].

\subsection{TEAP of the prostate}

There was no randomized trial to compare the TEAP with TURP, and their effects on male sexual function. Only two cohort studies with TEAP were identified, with a total of 104 patients in the studies [33, 34]. The follow-up was for 3 and 12 months, respectively. One study with a small patient population $(n=10)$ and short follow-up (3 months) reported painful ejaculation in one patient, and no incidence of retrograde ejaculation [33]. Another study was a multicenter cohort with 94 patients followed up for 12 months [34]. There were three patients complaining of erectile dysfunction: two patients with hematospermia and only one patient who reported retrograde ejaculation.

\section{Discussion}

Most men are likely to be faced with LUTS due to $\mathrm{BPH}$ as early as in their fourth decade [1]. The sexual function of men has been shown to be independently associated with LUTS $[1,4]$. Yet, the procedures performed for the surgical management of $\mathrm{BPH}$ themselves are associated with altering sexual function, keeping in mind that deterioration in sexual function is a normal process of aging. Many trials have been performed comparing the various minimally invasive surgical therapies for symptomatic BPH with the 'gold standard'-TURP [3]. Most of these trials were excellent studies to determine the efficacy of the various procedures when it comes to relieving LUTSs, but often did not address the sexual function of the patient in such a way as to allow standardized analysis. Trials that utilized validated questionnaires to assess sexual function include the IIEF, DanPSS Sex, Baseline Sexual Function Questionnaire (BSFQ) and Sapporo Medical University Sexual Function Questionnaire. However, validated questionnaires were not used in many other studies, and few studies provided baseline erectile function for patients before their procedures, making compiling data difficult to evaluate the overall sexual impact of each procedure performed for symptomatic BPH. Commenting on global erectile 
function and ejaculatory dysfunction as general terms without objective data or clear definitions does not allow for comparison or validation, as there needs to be a standardization of the data. Nevertheless, ordinal data such as decrease or increase of erectile function or new onset of erectile dysfunction and retrograde ejaculation after each procedure can be compiled to analyze the impact of these minimally invasive surgeries on male sexual function, particularly when the studies were performed to compare with the 'gold standard'-TURP. Therefore, certain trends and statements can be made based on our systemic review regarding minimally invasive surgery for BPH in terms of sexual function.

Globally, the impacts of the holmium laser and TURP on male sexual function were about the same, with averages of $7.5 \%$ and $7.7 \%$ of patients reporting decreased erectile function, and $7.1 \%$ and $6.2 \%$ of patients reporting increased erectile function after each surgery. Both holmium laser and TURP surgeries caused high incidences of ejaculatory dysfunction $(>50 \%)$ and the patients should be well informed regarding this adverse effect before accepting these procedures. KTP laser appeared to bring no overall change in patients' erectile function, but caused a high incidence of ejaculatory dysfunction $(>30 \%)$ [14-16]. There is not enough information to make a statement regarding the sexual function of patients receiving thulium laser surgery, but limited data suggest a high incidence of retrograde ejaculation (55\%); however, this is still lower when compared with patients who received TURP treatments $(65 \%)$ for their BPH [19]. We believe the high incidence of ejaculatory dysfunction after these laser procedures is related to their comparable effectiveness with TURP to treat $\mathrm{BPH}$, because the more effective the procedure in relieving the LUTS, the higher the incidence of ejaculatory dysfunction encountered in clinical practice. The effect of ND:YAG laser for BPH on male erectile function is small and comparable to TURP, but with much less incidence of ejaculatory dysfunction (about 15\%) when compared with TURP [21-24]. This is associated with its ineffectiveness in the treatment of BPH [3], and should not be considered as its advantage over the TURP.

As a non-laser type of minimally invasive surgery, TUMT has less adverse effects on sexual function, with about $8.7 \%$ of patients reporting decreased erectile function and $17.8 \%$ of patients reporting ejaculatory dysfunction compared with patients who received TURP, which had $19.3 \%$ of patients with erectile dysfunction and
$42.7 \%$ with ejaculatory dysfunction $[23,24,26,27]$. This phenomenon is also observed in patients who received TUNA procedures, wherein only $5.8 \%$ of patients reported decreased erectile function and $5.6 \%$ of patients reported ejaculatory dysfunction compared with TURP, which had $18.2 \%$ of patients with erectile dysfunction and $39.7 \%$ of patients with ejaculatory dysfunction in the given studies $[24,30-32]$. Not surprisingly, there are also $7.9 \%-15.2 \%$ of patients reporting increased erectile function after TUNA and TUMT. As mentioned earlier, LUTS in men is closely associated with erectile dysfunction; therefore, resolution of LUTS may improve the erectile function [1, 4]. For the effects of other types of minimally invasive procedures for the treatment of $\mathrm{BPH}$, such as TEAP and HIFU, on sexual function in men, it is not possible to make any meaningful statement at present as there is no randomized trial to compare their effects with those of TURP.

\section{Conclusion}

Available studies suggest that minimally invasive surgeries for the treatment of BPH have comparable effects to TURP on male erectile function. Patients can have either a decrease or an increase in their erectile function after laser procedures, TUMT, TUNA and TURP, although it would seem that the majority of men will experience no change. As observed with TURP, a high incidence of ejaculatory dysfunction is common after treatment of BPH with effective laser surgeries such as holmium, KTP and thulium therapy. The TUMT, TUNA and less effective laser surgeries (ND:YAG visual laser ablation or interstitial laser coagulation) for the treatment of BPH have less incidence of ejaculatory dysfunction. However, with the data available, it is difficult to make a definite correlation between procedures used to treat symptomatic BPH and sexual function. More studies with longer follow-up are needed to better understand how the procedures we perform for symptomatic BPH affect the sexual function of our patients. A validated sexual assessment tool used before the treatment and during follow-up visits should be recommended for every patient with symptomatic BPH. For now, selection of each patient into a specific minimally invasive surgery should depend not only on the patient's age, overall health, size of the prostate, severity of symptoms, comorbidity, coagulation status, risk of prostate cancer, financial situation and surgeon's expertise and preference 
[3], but also on the patient's sexual function status and the potential impact of each procedure on male sexual function. This will enable both the physicians and patients to better understand the impact of LUTS due to $\mathrm{BPH}$, and the procedures utilized to treat them on sexual function.

\section{References}

1 Taylor JM, DeSouza R, Wang R. Common approach to managing lower urinary tract symptoms and erectile dysfunction. Asian J Androl 2008; 10: 45-53.

2 Martin DJ, Mulhall JP. Enlarging the scope of managing benign prostatic hyperplasia: addressing sexual function and quality of life. Int J Clin Pract 2005; 59: 579-90.

3 Berardinelli F, Hinh P, Wang R. Minimally invasive surgery in the management of benign prostatic hyperplasia. Minerva Urol Nefrol 2009; 61: 269-89.

4 Basson R, Rees R, Wang R, Montejo AL, Incrocci L. Sexual function in chronic illness. J Sex Med 2010; 7: 374-88.

5 Mottet N, Anidjar M, Bourdon O, Francois JF, Teillac P, et al. Randomized comparison of transurethral electrorection and holmium: YAG laser vaporization for symptomatic benign prostatic hyperplasia. J Endourol 1999; 13: 127-30.

6 Gillings PJ, Kennett KM, Fraundorfer MR. Holmium laser resection versus transurethral resection of the prostate: results of a randomized trial with 2 years of follow-up. J Endourol 2000; 14: 757-60.

7 Tan AH, Gilling PJ, Kennett KM, Frampton C, Westenberg $\mathrm{AM}$, et al. A randomized trial comparing holmium laser enucleation of the prostate with transurethral resection of the prostate for the treatment of bladder outlet obstruction secondary to benign prostatic hyperplasia in large glands (40 to 200 grams). J Urol 2003; 170: 1270-4.

8 Kuntz RM, Ahyai S, Lehrich K, Fayad A. Transurethral holmium laser enucleation of the prostate versus transurethral electrocautery resection of the prostate: a randomized prospective trial in 200 patients. J Urol 2004; 172: 1012-6.

9 Westenberg A, Gilling P, Kennett K, Frampton C, Fraundorfer M. Holmium laser resection of the prostate versus transurethral resection of the prostate: results of a randomized trial with 4-year minimum long-term follow-up. J Urol 2004; 172: 616-9.

10 Montorse F, Naspro R, Salonia A, Suardi N, Briganti A, et al. Holmium laser enucleation versus transurethral resection of the prostate: results from a 2-center, prospective, randomized trial in patients with obstructive benign prostatic hyperplasia. J Urol 2004; 172: 1926-9.

11 Briganti A, Naspro R, GallinaA, Salonia A, Vavassori I, et al. Impact of sexual function of holmium laser enucleation versus transurethral resection of the prostate: results of a prospective, 2-center, randomized trial. J Urol 2006; 175: 1817-21.

12 Wilson LC, Gilling PJ, Williams A, Kennett KM, Frampton $\mathrm{CM}$, et al. A randomized trial comparing holmium laser enucleation versus transurethral resection in the treatment of prostates larger than 40 grams: results at 2 years. Eur Urol 2006; 50: 569-73.

13 Meng F, Gao B, Fu Q, Liu Y, Shi B, et al. Change of sexual function in patients before and after Ho:YAG laser enucleation of the prostate. J Androl 2007; 28: 259-61.

14 Shingleton WB, Farabaugh P, May W. Three-year follow-up of laser prostatectomy versus transurethral resection of the prostate in men with benign prostatic hyperplasia. Urology 2002; 60: 305-8.

15 Bouchier-Hayes DM, Anderson P, Van Appledorn S, Bugeja P, Costello AJ. KTP laser versus transurethral resection: early results of a randomized trial. J Endourol 2006; 20: $580-5$.

16 Horasanli K, Silay MS, Altay B, Tanriverdi O, Sarica K, et al. Photoselective potassium titanyl phosphate (KTP) laser vaporization versus transurethral resection of the prostate for prostates larger than $70 \mathrm{~mL}$ : a short-term prospective randomized trial. Urology 2008; 71: 247-51.

17 Malek RS, Kuntzman RS, Barrett DM. High power potassium-titanyl-phosphate laser vaporization prostatectomy. J Urol 2000; 163: 1730-3.

18 Hamann MF, Naumann CM, Seif C, van der Horst C, Junemann $\mathrm{KP}$, et al. Functional outcome following photoselective vaporization of the prostate (PVP): urodynamic findings within 12 months follow-up. Eur Urol 2008; 54: 902-10.

19 Xia SJ, Zhuo J, Sun XW, Han BM, Shao Y, et al. Thulium laser versus standard transurethral resection of the prostate: a randomized prospective trial. Eur Urol 2008; 53: 382-90.

20 Fu WJ, Hong BF, Yang Y, Zhang X, Gao JP, et al. Vaporesection for managing benign prostatic hyperplasia using a $2-\mu \mathrm{m}$ continuous-wave laser: a prospective trial with 1-year follow-up. BJU Int 2009; 103: 352-6.

21 Cowles RS, Kabalin JN, Childs S, Lepor H, Dixon C, et al. A prospective randomized comparison of transurethral resection to visual laser ablation of the prostate for the treatment of benign prostatic hyperplasia. Urology 1995; 46: 155-60.

22 Sengor F, Kose O, Yucebas E, Beysel M, Erdogan K, et al. A comparative study of laser ablation and transurethral electroresection for benign prostatic hyperplasia: results of a 6-month follow-up. Br J Urol 1996; 78: 398-400.

23 Norby B, Nielsen HV, Frimodt-Moller PC. Transurethral interstitial laser coagulation of the prostate and transurethral microwave thermotherapy $v s$. transurethral resection or incision of the prostate: results of a randomized, controlled study in patients with symptomatic benign prostatic hyperplasia. BJU Int 2002; 90: 853-62.

24 Arai Y, Aoki Y, Okubo K, Maeda H, Terada N, et al. Impact of interventional therapy for benign prostatic hyperplasia on quality of life and sexual function: a prospective study. J Urol 2000; 164: 1206-11.

25 Kabalin JN, Bite G, Doll S. Neodymium: YAG laser coagulation prostatectomy: 3 years of experience with 227 patients. J Urol 1996; 155: 181-5.

26 Ahmed M, Bell T, Lawrence WT, Ward JP, Watson GM. Transurethral microwave thermotherapy (Prostatron version 2.5) compared with transurethral resection of the prostate for the treatment of benign prostatic hyperplasia: a randomized, 
controlled, parallel study. Br J Urol 1997; 79: 181-5.

27 Mattiasson A, Wagrell L, Schelin S, Nordling J, Richthoff J, et al. Five-year follow-up of feedback microwave thermotherapy versus TRUP for clinical BPH: a prospective randomized multicenter study. Urology 2007; 69: 91-6.

28 Roehrborn CG, Preminger G, Newhall P, Denstedt J, Razvi H, et al. Microwave thermotherapy for benign prostatic hyperplasia with the Dornier Urowave: results of a randomized, double-blind, multicenter, sham-controlled trial. Urology 1998; 51: 19-28.

29 Netto NR, Claro J, Cortado PL. Ejaculatory dysfunction after transurethral microwave thermotherapy for treatment of benign prostatic hyperplasia. J Endourol 1994; 8: 217-9.

30 Bruskewitz R, Issa MM, Roehrborn CG, Naslund MJ, Perez-Marrero R, et al. A prospective, randomized 1-year clinical trial comparing transurethral needle ablation to transurethral resection of the prostate for the treatment of symptomatic benign prostatic hyperplasia. J Urol 1998; 159: 1588-93, discussion 1594.
31 Cimentepe E, Unsal A, Saglam R. Randomized clinical trial comparing transurethral needle ablation with transurethral resection of the prostate for the treatment of benign hyperplasia: results at 18 months. J Endourol 2003; 17: 103-7.

32 Hill B, Belville W, Bruskewitz R, Issa M, Perez-Marrero $\mathrm{R}$, et al. Transurethral needle ablation versus transurethral resection of the prostate for the treatment of symptomatic benign prostatic hyperplasia: 5-year results of a prospective, randomized, multicenter clinical trial. J Urol 2004; 171 : 2336-40.

33 Goya N, Ishikawa N, Ito F, Ryoji O, Tokumoto T, et al. Ethanol injection therapy of the prostate for benign prostatic hyperplasia: preliminary report on application of a new technique. J Urol 1999; 162: 383-6.

34 Grise P, Plante M, Palmer J, Martinez-Sagarra J, Hernandez $\mathrm{C}$, et al. Evaluation of the transurethral ethanol ablation of the prostate (TEAP) for symptomatic benign prostatic hyperplasia (BPH): a European multi-center evaluation. Eur Urol 2004; 46: 496-501; discussion 501-2. 